\title{
STUDY PROFILE OF RECURRENT ABDOMINAL PAIN IN CHILDREN EXAMINED BY CLINICAL EXAMINATION AND ULTRASONOGRAPHY
}

\author{
Gunjan Kela Mehrotra1, Aayush Gupta2, Parul Jain ${ }^{3}$, Swati Mulye ${ }^{4}$ \\ ${ }_{1}^{1}$ Associate Professor, Department of Paediatrics, SAMC \& PGI, Indore. \\ 2Junior Resident, Department of Paediatrics, SAMC \& PGI, Indore. \\ 3Junior Resident, Department of Paediatrics, SAMC \& PGI, Indore. \\ ${ }^{4}$ Professor, Department of Paediatrics, SAMC \& PGI, Indore.
}

\begin{abstract}
\section{BACKGROUND}

Abdominal pain is perhaps the most common painful health problem in school-aged children. J Apley, a British paediatrician, studied abdominal pain among children extensively and observed that approximately $10 \%$ of school aged children get recurrent episodes of abdominal pain. He named this symptom complex as recurrent abdominal pain (RAP) syndrome and defined it as "at least three episodes of abdominal pain, severe enough to affect their activities over a period longer than three months" Pain localization in younger children is poor, and in a suffering child, physical examination is often limited. Thus, sonographic evaluation of the abdomen is frequently performed in children to investigate the reason for the pain and to exclude other acute abdominal surgical conditions. The main clinical concerns are acute appendicitis, intussusception, and torsion of the ovary. With the routine use of high-frequency transducers, detection of enlarged abdominal lymph nodes (EALNs) is very common. When enlarged nodes are found with no other abnormality detected, the term "mesenteric lymphadenitis" is often used to describe an inflammatory process of abdominal lymph nodes.

The aim of this study was to evaluate the profile of recurrent abdominal pain in children examined by clinical examination and ultrasonography.
\end{abstract}

\section{MATERIALS AND METHODS}

We prospectively studied 100 patients within age range from 1 to 16 years and attending paediatric department at Sri Aurobindo Institute of Medical Sciences and Hospital, Indore, Madhya Pradesh, India from July 2016 to June 2017 presenting with abdominal pain of various aetiological causes subjected to clinical and ultrasonographic examination were included in this study.

\section{RESULTS}

Most common area of lymph nodes seen on USG was right lower quadrant of abdomen [80 \%]. Maximum numbers (46\%) of patients are from 5-8 years age group. More number of boys (54\%) is affected as compared with the girls. Maximum (62\%) patients had total of 1-5 episodes and next infrequency are patients of multiple episodes, $30 \%$ of patients had school loss due to pain abdomen. Periumbilical and right lower quadrant of the abdomen was most commonly affected ( $35 \%$ each).

\section{CONCLUSION}

We can conclude that -EALNs are frequently seen children with pain abdomen 5- 8 yrs. with boys more commonly affected than girls. Most patients presented with 1-5 episodes, $30 \%$ of patients had school loss due to pain abdomen. Periumbilical and Right lower quadrant of the abdomen was most commonly affected (35\% each).

\section{KEYWORDS}

Abdominal Pain, Enlarged Abdominal Lymph Nodes, Ultrasonography, Periumbilical.

HOW TO CITE THIS ARTICLE: Mehrotra GK, Gupta A, Jain P, et al. Study profile of recurrent abdominal pain in children examined by clinical examination and ultrasonography. J. Evolution Med. Dent. Sci. 2018;7(07):860-863, DOI: 10.14260/jemds/2018/196

\section{BACKGROUND}

Abdominal pain is perhaps the most common painful health problem in school-aged children. J Apley, a British paediatrician, studied abdominal pain among children extensively and observed that approximately $10 \%$ of school aged children get recurrent episodes of abdominal pain. He abdominal pain, severe enough to affect their activities over a

'Financial or Other Competing Interest': None.

Submission 07-01-2018, Peer Review 01-02-2018,

Acceptance 06-02-2018, Published 12-02-2018.

Corresponding Author:

Dr. Gunjan Kela Mehrotra,

\#201 A Block, Om Gurudev Complex,

SCH 54, Vijay Nagar,

Indore-452010, M. P.

E-mail: drgunjankela@yahoo.com

DOI: $10.14260 /$ jemds $/ 2018 / 196$

(c) (i) () $\Theta$ named this symptom complex as recurrent abdominal pain (RAP) syndrome and defined it as "at least three episodes of period longer than three months".[1] His findings formed the main guidelines for the practising paediatricians and researchers dealing with this problem. Even though, the term chronic is used when referring to RAP, each episode of pain is distinct and separated by periods of wellbeing. Pain localization in younger children is poor, and in a suffering child, physical examination is often limited. Thus, sonographic evaluation of the abdomen is frequently performed in children to investigate the reason for the pain and to exclude other acute abdominal surgical conditions.[2]

The prevalence of RAP in children ranges from 10 to $20 \%$. An organic lesion is present in 5 to $10 \%$ of children.[3] RAP has been found to be common in the setting of school phobia, sibling rivalry and a family history of multiple abdominal complaints, psychological problems and disturbed 
interpersonal relationships. Recurrent abdominal pain may be manifested as isolated paroxysms of periumbilical pain, as pain in the abdomen, pain with dyspepsia, and abdominal pain with dysfunction of the digestive tract. The incidence of organic and non-organic causes is variable in different studies. Hence proper evaluation is very important for the diagnosis and management of this vexing problem. The Rome III criteria ${ }^{[4]}$ now categorize abdominal pain into

1. Functional dyspepsia (FD).

2. Functional abdominal pain (FAP) and functional abdominal pain syndrome (FAPS).

3. Irritable bowel syndrome (IBS).

4. Abdominal migraine.

The main clinical concerns are acute appendicitis, intussusception, and torsion of the ovary. With the routine use of high-frequency transducers, detection of enlarged abdominal lymph nodes (EALNs) is very common. When enlarged nodes are found with no other abnormality detected, the term "mesenteric lymphadenitis" is often used to describe an inflammatory process of abdominal lymph nodes.

However, there is some disagreement in the medical literature about the importance of finding EALNs and use of the term "mesenteric adenitis." In the paediatric literature, the term is reserved for specific inflammation of the mesenteric lymph nodes, caused by Yersinia, Staphylococcus, Salmonella, different types of mycobacteria, and viruses. $[5,6,7]$ In the radiologic literature, the term is mainly applied simply to describe lymph nodes greater than $5 \mathrm{~mm}$ in diameter.[8,9,10]

\section{Objective}

To study the profile of recurrent abdominal pain in children examined by clinical examination and ultrasonography

\section{MATERIALS AND METHODS}

Study Period

July 2016 to June 2017.

\section{Study Design}

Prospective observational study.

\section{Place of Study}

Department of paediatrics, SAMC \&PGI Indore [M. P.]

\section{Inclusion Criteria}

Children between 1- 14 yrs. of age who came Medical College OPD in the department of paediatrics with abdominal pain are included.

\section{Exclusion Criteria}

Children less than 1 yr. and more than 14 yrs. of age.

Patient's demographic profile, clinical features and ultrasonography of abdomen were evaluated. Final diagnosis was established, and patients were followed in OPD. All lymph nodes were evaluated and measured in transverse and anteroposterior dimensions. Lymph nodes of size $>5 \mathrm{~mm}$ were documented. Other relevant findings such as free fluid and positive probe tenderness were also recorded.
RESULTS

\begin{tabular}{|c|c|c|}
\hline Age Group & Number & Percentage \% \\
\hline $1-4$ & 22 & 22 \\
\hline $5-8$ & 46 & 46 \\
\hline $9-12$ & 20 & 20 \\
\hline $13-16$ & 12 & 12 \\
\hline Total & $\mathbf{1 0 0}$ & $\mathbf{1 0 0}$ \\
\hline \multicolumn{3}{|c|}{ Table 1 Age Distribution [n=100] } \\
\hline
\end{tabular}

Table 1 is showing maximum number (46\%) of patients are from 5-8 years age group and incidence decrease as the age advance and only $12 \%$ are affected after the age of 13 years.

\begin{tabular}{|c|c|c|}
\hline Gender & Number & Percentage \% \\
\hline Boys & 54 & 54 \\
\hline Girls & 46 & 46 \\
\hline Total & $\mathbf{1 0 0}$ & $\mathbf{1 0 0}$ \\
\hline \multicolumn{2}{|r|}{ Table 2. Gender Distribution [N=100] } \\
\hline
\end{tabular}

In above table the boys (54\%) are affected as compared with the girls.

\begin{tabular}{|c|c|c|}
\hline Episodes & Number & Percentage \% \\
\hline $1-5$ & 62 & 62 \\
\hline $6-10$ & 14 & 14 \\
\hline $11-15$ & 04 & 04 \\
\hline Multiple & 20 & 20 \\
\hline Total & $\mathbf{1 0 0}$ & $\mathbf{1 0 0}$ \\
\hline \multicolumn{3}{|c|}{ Table 3. Distribution according to number of episodes. } \\
[n=100]
\end{tabular}

In the Table 3 , it can be seen that- maximum (62\%) patients had total of 1-5 episodes and next infrequency are patients of multiple episodes.

\begin{tabular}{|c|c|c|}
\hline $\begin{array}{c}\text { Duration of Episodes } \\
\text { [in minute] }\end{array}$ & Number & Percentage \% \\
\hline $1-10$ & 28 & 28 \\
\hline $11-20$ & 22 & 22 \\
\hline $21-30$ & 24 & 24 \\
\hline$>30$ & 26 & 26 \\
\hline Total & $\mathbf{1 0 0}$ & $\mathbf{1 0 0}$ \\
\hline \multicolumn{2}{|c|}{ Table 4. Distribution of patients according to } \\
duration of episodes. [n=100]
\end{tabular}

\begin{tabular}{|c|c|c|}
\hline School Loss & Number & Percentage \\
\hline No & 70 & 70 \\
\hline Yes & 30 & 30 \\
\hline Total & $\mathbf{1 0 0}$ & $\mathbf{1 0 0}$ \\
\hline \multicolumn{2}{|c|}{ Table 5. Distribution of patients according } \\
to school loss. [n=100] \\
\hline
\end{tabular}

Above table showing $30 \%$ of patients had school loss due to pain abdomen.

\begin{tabular}{|c|c|c|}
\hline Site of Abdomen & Number & Percentage \\
\hline Periumbilical & 35 & 35 \\
\hline Right upper & 10 & 10 \\
\hline Right lower & 35 & 35 \\
\hline Left upper & 11 & 11 \\
\hline Left lower & 09 & 09 \\
\hline
\end{tabular}

Table 6. Distribution according to site localisation [n=100]

Right lower quadrant of the abdomen and periumbilical region were most commonly distributed site $(35+35=70 \%)$. 


\begin{tabular}{|c|c|c|}
\hline Location of Lymph Node & Number & Percentage \% \\
\hline Right lower quadrant & 80 & 80 \\
\hline Left lower quadrant & 12 & 12 \\
\hline paraumbilical & 8 & 8 \\
\hline \multicolumn{3}{|c|}{$\begin{array}{l}\text { Table 7. Showing location of lymph nodes based } \\
\text { on ultra-sonography }(n=100)\end{array}$} \\
\hline
\end{tabular}

The largest proportion of the nodes was seen in the right lower quadrant, followed by left lower quadrant. A review of the dimensions of the lymph nodes detected shows that the transverse diameter was by and large always greater than the antero-posterior diameter. The maximum transverse diameter values were seen between 10- $14 \mathrm{~mm}$ whereas antero-posterior diameter value was seen between 4-8 $\mathrm{mm}$.

\section{DISCUSSION}

In western world Yersinia enterocolitica is the main causative organism for mesenteric adenitis.[11] In 1921 Mesenteric adenitis was first reported by Brennemann, also known as Brennemann syndrome. The disease is primarily associated with acute appendicitis, intussusception and lymphoma. In the first decade of life mesenteric adenitis is more common than appendicitis in view of proliferative response of bodily lymphoid tissue. After first decade the condition is relatively uncommon and rarely seen in second decade. In children, simple or nonspecific mesenteric adenitis often viral in origin is the most frequently encountered entity responsible for a large percentage of the cases of "medical bellyache" seen in routine practice.[12]

It is observed that same etiological agent which causes swelling of the lymphoid tissue of Peyer's patches can act as etiological factor for mesenteric adenitis induced intussusception in children. Mesenteric nodes can be enlarged because of adenoviral infections, Crohn's disease, appendicitis, gastroenteritis; Yersinia infections, AIDS, or it can be due to incidental finding in asymptomatic children. ${ }^{[2]}$ Clinically the various clinical features suggestive of nonspecific mesenteric adenitis are clean tongue, deep tenderness in right iliac fossa radiating towards the umbilicus, the absence of rigidity and palpable glands.[13]

In our study, most common affected age group was seen between 5 years to 8 years (46\%), and thereafter there was a decrease in incidence. This finding is similar to study by Roshani chanchlani.[14]

In our study most commonly affected are boys than girls [54\%] which also seen in study by Vayner et al.[15]

Regarding size, number and location of enlarged mesenteric nodes, present study findings correlate with findings of Aired I et al.[16] Regarding duration of episodes and frequency of episodes there is no published literature available for comparison but from present study, it was concluded from findings that- most patients had symptoms lasting from 1-10 minutes, $30 \%$ of patients suffered school loss due to pain abdomen.

Most commonly affected area of abdomen quadrant is periumbilical and right iliac fossa 70 region in our study [70\%] which correlate with study by Chanchlani R et al.[15]

\section{CONCLUSION}

Mesenteric lymphadenitis is a common medical cause of abdominal pain in paediatric patients. It is a common self- limiting inflammatory process frequently caused by viral pathogen, affecting mesenteric lymph nodes in the abdomen. Mesenteric adenitis has never been proved to be responsible for any mortality nor have any complications been attributed to it. Ultrasonography is the best tool to rapidly differentiate the disease from acute appendicitis and if diagnosed accurately, surgical intervention can be avoided as majority of cases resolve with conservative treatment.

This study was performed to evaluate the importance of detection of EALNs in children with abdominal pain using USG. We can conclude that -EALNs are frequently seen children with pain abdomen 5-8 years with boys more commonly affected than girls. Most patients presented with 1-5 episodes, $30 \%$ of patients had school loss due to pain abdomen. Periumbilical and right lower quadrant of the abdomen was most commonly affected (70\%).

\section{REFERENCES}

[1] Apley J, Naish N. Recurrent abdominal pain: a field survey of 1000 school children. Arch Dis Child 1958;33(168):165-70.

[2] Carty HM. Paediatric emergencies: non-traumatic abdominal emergencies. Eur Radiol 2002;12(12):2835-48.

[3] Apley J. The child with abdominal pains. London: Blackwell scientific publications 1975.

[4] Ammoury RF, Pfefferkorn Mdel R, Croffie JM. Functional gastrointestinal disorders: past and present. World J Pediatr 2009;5(2):103-12.

[5] Arda IS, Ergin F, Varan B, et al. Acute abdomen caused by Salmonella typhimurium infection in children. J Pediatr Surg 2001;36(12):1849-52.

[6] Hervas JA, Alberti P, Bregante JI, et al. Chronic intussusception associated with Yersinia enterocolitica mesenteric adenitis. J Pediatr Surg 1992;27(12):1591-2.

[7] Puylaert JB, Lalisang RI, van der Werf SD, et al. Campylobacter ileocolitis mimicking acute appendicitis: differentiation with graded-compression US. Radiology 1988;166(3):737-40.

[8] Sivit CJ, Newman KD, Chandra RS. Visualization of enlarged mesenteric lymph nodes at US examination. Pediatr Radiol 1993;23(6):471-5.

[9] Healy MV, Graham PM. Assessment of abdominal lymph nodes in a normal paediatric population: an ultrasound study. Australas Radiol 1993;37(2):171-2.

[10] Watanabe M, Ishii E, Hirowatari Y. Evaluation of abdominal lymphadenopathy in children by ultrasonography. Pediatr Radiol 1997;27(11):860-4.

[11] Puylaert JB, Van der zant FM, Mutsaers JA. Infectious ileocecitis caused by Yersinia, Campylobacter and Salmonella: clinical, radiological and us findings. European J Radiol 1997;7(1):3-9.

[12] Zhang LY, Hongguang S. Mesenteric lymph nodes in children with intussusception and its clinical significance. Journal Clinical Med 2008;12(3):104-5.

[13] Pradel JA, David XR, Taourel P, et al. Sonographic assessment of the normal and abnormal bowel wall in non-diverticular ileitis and colitis. Abdominal Imaging 1997;22(2):167-72. 
[14] Chanchlani R. Clinical profile and management of mesenteric lymphadenitis in children-our experience. Int J Orthop Traumatol Surg Sci 2015;1(1):1-4.

[15] Vayner N, Coret A, Polliack G. Mesenteric lymphadenopathy in children examined by US for chronic and/or recurrent abdominal pain. Pediatr Radiol 2003;33(12):864-7.
[16] Aird I. Acute non-specific mesenteric lymphadenitis. Br Med J 1945:2(4428):680-2. 